\title{
HIGH-FREQUENCY TRANSFER OF NEOMYCIN RESIST- ANCE BETWEEN NATURALLY OCCURRING STRAINS OF STAPHYLOCOCCUS AUREUS
}

\author{
R. W. LACEY \\ Department of Bacteriology, University of Bristol
}

THE resistance of bacteria to some antibiotics, in the form in which it occurs naturally, appears rarely to have arisen de novo by mutation. Present evidence suggests that it has more frequently been acquired by some form of gene transfer between cells. Among the enterobacteria, the acquisition of resistance results from the transfer of genetic determinants by conjugation, possibly by means of a pilus bridge between the cells. This method of gene transfer has not been detected among Gram-positive bacteria, and it is uncertain how the spread of antibiotic resistance has occurred in these species.

Transfer of resistance can be brought about in vitro by means of transduction by prophages, but convincing proof that this mechanism operates in vivo is lacking. The frequency of transduction obtained in most laboratory experiments is considered by some to be too low to account for the observed spread of resistance among bacterial strains (see Richmond, 1969). Occasionally a phage may transfer a character at a much higher frequency; one such agent was constructed in the laboratory by the union of temperate phage with an extrachromosomal element (Novick, 1967). Possibly 10-50 per cent. of the resultant particles conferred erythromycin resistance on sensitive cells in broth cultures and in mice (Novick and Morse, 1967). If similar agents occurred naturally, they could be an important means by which transfer of resistance occurs between strains.

I have found that transfer of neomycin resistance can occur at high frequency among certain staphylococci isolated from hospital patients, and that a similar transfer occurs on the surface of the skin of volunteers. The gene vector is probably a staphylococcal bacteriophage carrying a neomycin-resistance determinant that exists in the resistant cell as part of a plasmid. Infection of sensitive strains with this agent could account for the acquisition of neomycin resistance by some staphylococcal strains in hospitals, particularly since resistant strains resembling those found in nature cannot be obtained by selection with the antibiotic in vitro.

\section{MATERIALS AND METHODS}

Staphylococci. Seventy-eight neomycin-resistant cultures of Staphylococcus aureus had been isolated in Bristol hospitals during 1967 and 1968. In preliminary experiments, three of them were found to donate neomycin resistance to sensitive staphylococci. All three had been obtained from the nose of different patients in a dermatological ward during routine screening. Each isolate was resistant to penicillin and neomycin \{minimum inhibitory concentration (MIC) $128 \mu \mathrm{g}$ neomycin per $\mathrm{ml}\}$, but was sensitive to streptomycin, tetracycline, erythromycin, cloxacillin and gentamicin, produced deep orange pigment on glycerol

Received 2 Feb. 1970; accepted 20 May 1970.

J. MED. MICROBIOL.-VOL. 4 (1971) 
monoacetate agar and gave phage reactions in group III (6/47/53/54/75/85). One of these isolates (no. $609 \mathrm{~N}_{\mathrm{D}}$ ) has been examined in detail. Neomycin-sensitive variants appeared spontaneously in these cultures in the laboratory; no. 609S was a laboratory-selected streptomycin-resistant variant of no. $609 \mathrm{~N}_{\mathrm{D}}$ that had lost its neomycin resistance. Other recipient strains included neomycin-sensitive staphylococci isolated from Bristol hospitals in 1969 , and the propagating strains (PS) of phages no. 80, 52, 3A, 3C, 55, 47, 53, 54, 77, 83A and 85 in the International Basic Set. In addition, six cultures that had been freeze-dried since their isolation in 1954 were used. Laboratory-selected streptomycin- or novobiocinresistant mutants were used where the wild-type recipient strain did not possess a suitable resistance marker for use in transfer experiments.

Bacteriophage typing was done by the method of Blair and Williams (1961) with the addition of three new typing phages, no. 83A, 84 and 85 (Report, 1967).

Antibiotic sensitivity was determined with Oxoid Multodiscs (penicillin 1.5 IU, cloxacillin $5 \mu \mathrm{g}$, neomycin $10 \mu \mathrm{g}$, erythromycin $10 \mu \mathrm{g}$, tetracycline $10 \mu \mathrm{g}$, streptomycin $10 \mu \mathrm{g}$ ) and Mast disks (gentamicin $10 \mu \mathrm{g}$, paromomycin $10 \mu \mathrm{g}$, kanamycin $30 \mu \mathrm{g}$ ). The MIC of the antibiotics was determined for a proportion of the strains by an agar-plate dilution method.

Transfer of neomycin resistance between staphylococci in nutrient broth. 1-ml volumes of overnight broth cultures of the donor and recipient strains were added to $100 \mathrm{ml}$ of Difco nutrient broth containing $0.01 \mathrm{M}-\mathrm{CaCl}_{2}$ in $250-\mathrm{ml}$ conical flasks. The final density of each culture was about $10^{7}$ colony-forming units per $\mathrm{ml}$. The mixed culture was placed in an incubator-shaker at $35^{\circ} \mathrm{C}$ and sampled after $18 \mathrm{hr}$ by dropping $0.02-\mathrm{ml}$ samples of neat and of diluted culture on to the appropriate selective nutrient agar. For example, when neomycin resistance was transferred from staphylococcus no. $609 \mathrm{~N}_{\mathrm{D}}$ (resistant to neomycin but sensitive to streptomycin) to a recipient sensitive to neomycin and resistant to streptomycin, the neomycin-resistant recipient organisms were detected by plating the mixture on medium containing both neomycin $(32 \mu \mathrm{g}$ per $\mathrm{ml})$ and streptomycin $(128 \mu \mathrm{g}$ per ml). Selective media for other mixtures contained tetracycline $(10 \mu \mathrm{g}$ per $\mathrm{ml})$ or novobiocin $(5 \mu \mathrm{g}$ per $\mathrm{ml})$ in addition to neomycin. Viable counts (Miles, Misra and Irwin, 1938) of the mixtures were determined on nutrient agar containing 1 per cent. ( $/ / \mathrm{v})$ glycerol monoacetate in order to identify the proportions of the strains by differences in their colonial pigment (Willis and Turner, 1963). As controls in each experiment, the donor and recipient strains were singly incubated and plated on the recovery medium. In other experiments, the spontaneously occurring neomycin-sensitive variant of the donor no. $609 \mathrm{~S}$ was incubated with each of three recipient cultures. The absence of neomycin-resistant organisms after 18 hours' incubation excluded the remote possibility that a character of the donor other than neomycin resistance affected the acquisition of neomycin resistance in the recipients.

Preparation of antisera against bacteriophages. Crude filtrates of the typing phages no. 47 (serological group A), no. 29 (serological group B), and no. 42D (serological group F), each containing about $10^{10}$ plaque-forming units per $\mathrm{ml}$ were prepared by the method of Williams and Rippon (1952). $1 \mathrm{ml}$ of each filtrate was injected daily into a rabbit for 7 days; after a further 7 days the rabbits were bled and the sera obtained showed a high titre of anti-phage activity.

Ultraviolet $(U V)$-induced lysates were prepared by the method of Novick (1963) by exposure to a $240 \mathrm{~V}$ Hanovia lamp at $25 \mathrm{~cm}$ distance for $5 \mathrm{~s}$.

Transfer of neomycin resistance between staphylococci inoculated on the skin. The method used was similar to that described previously (Lacey, 1968): about 105 organisms of donor and of recipient strains were separately centrifuged three times, resuspended twice in nutrient broth, and then in $0.02 \mathrm{ml}$ volumes of human serum. Areas on the forearms of subjects were seeded with the organisms, allowed to dry and then covered with a water-impervious label. Some areas were seeded with the donor or the recipient strain alone, and others were successively seeded with both strains, the recipient being allowed to dry before application of the donor. The label was left in position for $6 \mathrm{hr}$ and then removed and its under surface immediately placed on the surface of the appropriate selective medium and quickly removed. After overnight incubation of the plates, the resulting colonies were identified. 


\section{RESULTS}

Neomycin-resistant strains of Staph. aureus isolated from Bristol hospitals in 1967 and 1968

All the 78 resistant cultures were resistant to at least $64 \mu \mathrm{g}$ neomycin base per ml, produced normal-looking staphylococcal colonies on nutrient agar, and showed cross-resistance to kanamycin (MIC $>128 \mu \mathrm{g}$ per $\mathrm{ml}$ ) and to paromomycin (MIC $>32 \mu \mathrm{g}$ per $\mathrm{ml})$. Sixty-three of the strains were resistant to streptomycin, but all were sensitive to gentamicin. This cross-resistance pattern is similar to that of other naturally occurring strains (Chabbert, 1967). When grouped according to their phage-typing patterns and antibiotic sensitivities (table I), the neomycin-resistant staphylococci were classifiable into some 15 distinct strains. Phage-typing patterns were limited to groups I, III and I/III, and none belonged to group II or to the $52,52 \mathrm{~A}, 80,81$ complex.

\section{Selection of neomycin-resistant variants in vitro}

The phenotypic characters of the clinical isolates were markedly different from those of neomycin-resistant staphylococci obtained by exposure of sensitive organisms to aminoglucoside antibiotics in the laboratory. Those produced by exposure to moderate antibiotic levels (neomycin $2 \mu \mathrm{g}$ per $\mathrm{ml}$, kanamycin $8 \mu \mathrm{g}$ per $\mathrm{ml}$, or paromomycin $2 \mu \mathrm{g}$ per $\mathrm{ml}$ ) all showed abnormal colonial morphology; they differed in pigmentation and had a reduced growthrate when compared with the naturally occurring strains. Many comprised the small-colony variants previously described (Lacey, 1969a).

Attempts to produce rapidly growing neomycin-resistant forms by exposing sensitive cultures to higher concentrations of antibiotic (up to $64 \mu \mathrm{g}$ per $\mathrm{ml}$ of neomycin, $128 \mu \mathrm{g}$ per ml of kanamycin, or $32 \mu \mathrm{g}$ per ml of paromomycin) failed. Thus the type of neomycin resistance exhibited by the clinical isolates was quite distinct from that of any of the laboratory-produced variants.

\section{Transfer of neomycin resistance in broth cultures}

In preliminary experiments, a proportion of the bacteria of a neomycinsensitive culture were found to acquire neomycin resistance after incubation overnight in broth with one of the neomycin-resistant cultures. Sixteen neomycin-resistant cultures were in turn examined for their ability to donate the resistance to each of three neomycin-sensitive cultures when grown with them. Thirteen of the cultures, comprising one culture of strain 1 , the single culture of strain 6 , one culture of strain 8 , four cultures of strain 12, and one culture each of strains 13,14 and 15 (see table I), did not transfer resistance. On the other hand, three of the neomycin-resistant isolates, all of strain 3, were found to donate their resistance to recipient strains. Each of these donor cultures seemed to possess similar properties; one of them, no. $609 \mathrm{~N}_{\mathrm{D}}$, was investigated further. 
In a typical experiment, about $10^{7}$ organisms of no. $609 \mathrm{~N}_{\mathrm{D}}$ were incubated at $35^{\circ} \mathrm{C}$ with $10^{7}$ cells of a neomycin-sensitive recipient culture in $100 \mathrm{ml}$ nutrient broth. Recipients were chosen because they possessed a distinct phage-typing pattern and colonial pigmentation and possessed an appropriate

TABLE I

Neomycin-resistant staphylococci isolated from Bristol hospitals, 1967 and 1968

\begin{tabular}{r|l|l|c}
\hline $\begin{array}{c}\text { Strain } \\
\text { no. }\end{array}$ & Resistant to antibiotics* & Phage-typing pattern (at RTD) $\dagger$ & $\begin{array}{c}\text { Number of } \\
\text { isolates examined }\end{array}$ \\
\hline 1 & N & $29 / 52$ & 2 \\
2 & N & Untypable & 3 \\
3 & PN & $6 / 47 / 53 / 54 / 75 / 85$ & 6 \\
4 & TN & 52 & 1 \\
5 & TN & $29 / 52 \mathrm{~A} / 80 / 6 / 42 \mathrm{E} / 47 / 53 / 54 /$ & 1 \\
6 & PTN & $29 / 52$ & 1 \\
7 & PSEN & $6 / 42 / 47 / 54 / 85 / 81$ & 1 \\
8 & PSTN & 85 & 3 \\
9 & PSTN & $75 / 77 / 84 / 85$ & 1 \\
10 & PTEN & $84 / 85$ & 1 \\
11 & PSTEN & $84 / 85$ & 25 \\
12 & PSTEN & $81 / 6 / 42 \mathrm{E} / 47 / 54 / 85$ & 18 \\
13 & PSTEN & Untypable & 7 \\
14 & PSTEN & $77 / 84 / 85$ & 6 \\
15 & PSTEN & $52 / 79 / 6 / 47 / 53 / 54 / 83 \mathrm{~A} / 85$ & 2 \\
\hline & & & 1 \\
\hline
\end{tabular}

* $\mathrm{P}=$ Penicillin $; \mathrm{S}=$ streptomycin; $\mathrm{T}=$ tetracycline; $\mathrm{E}=$ erythromycin; $\mathrm{N}=$ neomycin.

$\dagger \mathrm{RTD}=$ Routine test dilution.

and stable antibiotic-resistance marker. After overnight incubation, neomycinresistant recipient organisms were identified by plating the mixture on suitable selective nutrient agar. As controls, in each experiment the donor and recipient culture were separately incubated and then plated on to the selective medium.

Neomycin resistance was transferred from culture no. $609 \mathrm{~N}_{\mathrm{D}}$ to a variety of recipients (table II). The proportion of the various recipient cultures found to be resistant to neomycin after 18 hours' incubation with the donor was between $10^{-3.8}$ and $10^{-6 \cdot 7}$. The total numbers of the donor and recipients at this time varied between about $10^{8}$ and $10^{10}$ colony-forming units per $\mathrm{ml}$. Strains that typed in phage-group I or III or were non-typable could usually acquire resistance; but type $80 / 81$ and group II strains could not. Thus the 
phage-typing patterns of the cultures able to accept the resistance determinant in vitro were similar to those of the resistant clinical isolates. This suggested that the neomycin resistance of naturally occurring strains might have been acquired by a transfer mechanism. Examination of the neomycin-resistant recipients showed that their phage-typing pattern, colonial pigmentation and

TABLE II

Transfer of neomycin resistance from Staphylococcus aureus no. $609 N_{D}$ to recipient cultures during incubation in broth

\begin{tabular}{|c|c|c|c|}
\hline \multirow{2}{*}{ No. } & \multicolumn{2}{|c|}{ Recipient culture } & \multirow{2}{*}{$\begin{array}{l}\text { Proportion of recipient } \\
\text { culture that was neomycin } \\
\text { resistant after } 18 \text { hours' } \\
\text { incubation at } 35^{\circ} \mathrm{C} \text { with } \\
\text { donor strain } 609 \mathrm{~N}_{\mathrm{D}}\end{array}$} \\
\hline & Source & $\begin{array}{l}\text { Phage-typing pattern } \\
\text { (at RTD)** }\end{array}$ & \\
\hline $\begin{array}{l}1 \\
2 \\
3 \\
4 \\
5 \\
6\end{array}$ & $\begin{array}{l}\text { Bristol Hospitals, } 1954 \\
\text { Bristol Hospitals, } 1954 \\
\text { Bristol Hospitals, } 1954 \\
\text { Bristol Hospitals, } 1954 \\
\text { Bristol Hospitals, } 1954 \\
\text { Bristol Hospitals, } 1954\end{array}$ & $\begin{array}{l}29 / 47 / 54 / 85 \\
29 / 85 \\
75 / 77 / 84 / 85 \\
\text { Untypable } \\
6 / 47 / 54 / 75 \\
47 / 75 / 77 / 84 / 85\end{array}$ & $\begin{array}{l}10^{-5.8} \\
10^{-5.3} \\
10^{-6.3} \\
10^{-6.7} \\
10^{-4.1} \\
10^{-4.2}\end{array}$ \\
\hline $\begin{array}{r}7 \\
8 \\
9 \\
10 \\
11 \\
12\end{array}$ & $\begin{array}{l}\text { Propagating strain no. 52A/79 } \\
\text { Propagating strain no. } 47 \\
\text { Propagating strain no. } 53 \\
\text { Propagating strain no. } 54 \\
\text { Propagating strain no. } 77 \\
\text { Propagating strain no. 83A }\end{array}$ & $\begin{array}{l}52 \mathrm{~A} / 79 \\
47 / 53 / 75 / 77 / 85 \\
53 / 54 / 75 / 77 / 85 \\
47 / 53 / 54 / 75 / 77 / 84 / 85 \\
77 \\
81 / 6 / 47 / 53 / 77 / 83 \mathrm{~A} / 85\end{array}$ & $\begin{array}{l}10^{-5.2} \\
10^{-5.4} \\
10^{-4.6} \\
10^{-4.2} \\
10^{-5.2} \\
10^{-6.1}\end{array}$ \\
\hline $\begin{array}{l}13 \\
14 \\
15 \\
16 \\
17 \\
18 \\
19 \\
20 \\
21\end{array}$ & $\begin{array}{l}\text { Bristol Hospitals, } 1969 \\
\text { Bristol Hospitals, } 1969 \\
\text { Bristol Hospitals, } 1969 \\
\text { Bristol Hospitals, } 1969 \\
\text { Bristol Hospitals, } 1969 \\
\text { Bristol Hospitals, } 1969 \\
\text { Bristol Hospitals, } 1969 \\
\text { Bristol Hospitals, } 1969 \\
\text { Bristol Hospitals, } 1969\end{array}$ & $\begin{array}{l}81 / 6 / 54 / 75 / 77 / 85 \\
47 / 53 / 54 / 75 / 77 / 84 \\
\text { Untypable } \\
\text { Untypable } \\
77 \\
29 / 77 \\
52 \mathrm{~A} / 77 \\
52 \mathrm{~A} / 79 \\
77 / 84 / 85\end{array}$ & $\begin{array}{l}10^{-3.8} \\
10^{-4.6} \\
10^{-5.2} \\
10^{-5.0} \\
10^{-5.8} \\
10^{-4.7} \\
10^{-5.5} \\
10^{-6.2} \\
10^{-5.6}\end{array}$ \\
\hline
\end{tabular}

* RTD = Routine test dilution.

sensitivity to antibiotics other than neomycin, kanamycin and paromomycinwere unchanged. All neomycin-resistant recipients were also resistant to kanamycin and paromomycin.

In the controls, no single-step mutants resistant to neomycin (at $32 \mu \mathrm{g}$ per $\mathrm{ml}$ ) were found in the recipient cultures. In the donor, mutation to streptomycin resistance was at a frequency of about 1 in $10^{9}$ colony-forming units and to novobiocin resistance was at about 1 in 1010 colony-forming units, but no tetracycline-resistant mutants were seen (at $10 \mu \mathrm{g}$ per $\mathrm{ml}$ ). These rare mutants were easily identified as they resembled the donor in pigmentation, in sensitivity to other antibiotics and in phage-typing pattern.

The neomycin-resistant recipients showed the same level of resistance to neomycin as the donor and exhibited similar instability, in that a proportion of the cells of broth cultures spontaneously lost their resistance. The resistant 
recipients could also donate their resistance to other neomycin-sensitive organisms in mixed broth cultures. Neomycin resistance, together with resistance to kanamycin and to paromomycin, could be transferred from these second-generation donors to several sensitive recipients; but transfer occurred at a somewhat lower rate and to a smaller range of organisms than that from no. $609 \mathrm{~N}_{\mathrm{D}}$. For example, 14 of 20 recipients that could accept neomycin resistance from no. $609 \mathrm{~N}_{\mathrm{D}}$ acquired resistance when incubated with one of the second-generation neomycin-resistant organisms and the proportion of the recipient culture that had acquired resistance was in the range $10^{-4.6}$ to $10^{-7.7}$. Two of the resultant neomycin-resistant recipients were investigated and were found to transfer their resistance (as third-generation donors) to some of the sensitive recipient cultures.

The neomycin-resistant donor no. $609 \mathrm{~N}_{\mathrm{D}}$ was lysogenic; UV-lysates of it contained a group-B phage that formed plaques on PS no. 83A and on a number of other staphylococci, including all 10 of the neomycin-resistant recipients that were tested. A similar phage was found in the neomycinsensitive mutant no. 609S. UV-lysates of three neomycin-resistant recipients that could act as second-generation donors were also lysogenic, but they carried different phages from no. $609 \mathrm{~N}_{\mathrm{D}}$. It seemed unlikely, therefore, that the groupB phage I detected in staphylococcus no. $609 \mathrm{~N}_{\mathrm{D}}$ was the agent solely responsible for the high-frequency transfer.

\section{Mechanism of the transfer of neomycin resistance}

The transfer of neomycin resistance to a recipient by a UV-induced lysate of no. $609 \mathrm{~N}_{\mathrm{D}}$ was investigated in an attempt to discover the mechanism of gene transfer.

A $1-\mathrm{ml}$ volume of the filtrate from no. $609 \mathrm{~N}_{\mathrm{D}}$ was added to $100 \mathrm{ml}$ of a 4-hr aerated culture of the neomycin-sensitive variant no. 609S containing about 108 organisms per $\mathrm{ml}$. The mixture was incubated at $35^{\circ} \mathrm{C}$ and sampled at intervals by dropping neat and diluted broth on to nutrient agar containing both neomycin and streptomycin. The acquisition of neomycin resistance by no. $609 \mathrm{~S}$ was complete after $15 \mathrm{~min}$.

A freshly prepared UV-induced filtrate of the donor, no. $609 \mathrm{~N}_{\mathrm{D}}$, contained about $10^{7}$ particles per $\mathrm{ml}$ that transferred neomycin resistance to no. 609S, but the transferring capacity of the filtrate rapidly declined with time. About 99.5 per cent. of the activity was lost every $24 \mathrm{hr}$ at room temperature.

The transfer of resistance from no. $609 \mathrm{~N}_{\mathrm{D}}$ to no. $609 \mathrm{~S}$ was dependent on the presence of calcium ions. And since the addition of micrococcal DNAase (Sigma Chemical Co.) to the lysate did not reduce the frequency of transfer, transduction was considered the likely mechanism. This conclusion was confirmed by using specific phage antisera to block transfer.

1-ml quantities of group A, B and $\mathrm{F}$ phage antisera were separately incubated with $9 \mathrm{ml}$ of the filtrate for $30 \mathrm{~min}$. at $37^{\circ} \mathrm{C}$. As a control, a portion of the filtrate was also incubated with serum from an unimmunised rabbit. Each of the mixtures was then added to $100 \mathrm{ml}$ of a 4-hr aerated culture of no. 609S 
containing about $10^{8}$ cells per ml. After 30 minutes' incubation, the cultures were plated on selective agar. The transfer of resistance to no. 609S was inhibited only by the antiserum inactivating serological group-B phages (table III). The results suggest that a phage of group $B$-though not the temperate phage that had been detected in no. $609 \mathrm{~N}_{\mathrm{D}}$-acted as a vector in these experiments.

\section{Nature of neomycin-resistance determinant}

Resistance to several antibiotics other than neomycin are thought to be determined by extrachromosomal elements or plasmids in Staph. aureus.

TABLE III

\begin{tabular}{|c|c|}
\hline $\begin{array}{l}\text { Antiphage } \\
\text { serum added }\end{array}$ & $\begin{array}{l}\text { No. of neomycin-resistant colonies of recipient } \\
\text { staphylococcus } 609 \mathrm{~S} \text { resulting from treatment } \\
\text { with } 1 \mathrm{ml} \text { of filtrate of staphylococcus no. } 609 \mathrm{~N}_{\mathrm{D}}\end{array}$ \\
\hline None & $6.8 \times 10^{6}$ \\
\hline Group A & $5.3 \times 10^{6}$ \\
\hline Group B & 0 \\
\hline Group F & $6 \cdot 2 \times 10^{6}$ \\
\hline
\end{tabular}

* A UV-induced filtrate of donor staphylococcus no. $609 \mathrm{~N}_{\mathrm{D}}$ was incubated with various antisera (diluted 1 in 10) for $30 \mathrm{~min}$. at $37^{\circ} \mathrm{C}$ before addition to a 4 -hr aerated culture of recipient staphylococcus no. 609S.

Evidence for their plasmid locus includes the spontaneous loss of the determinant in broth cultures, particularly at high temperatures, "curing" by various chemicals, and characteristic inactivation of the transducing ability by UV light (see review by Novick, 1969).

The neomycin resistance in staphylococcus no. $609 \mathrm{~N}_{\mathrm{D}}$ was investigated for the above features in an attempt to locate its genetic determinant in the cell. Portions of an initially fully resistant broth culture of no. $609 \mathrm{~N}_{\mathrm{D}}$ were incubated at various temperatures for $20 \mathrm{hr}$. Each culture was then diluted and plated on to the surface of nutrient agar to give discrete colonies after overnight incubation. Examination of about 1000 colonies from each culture showed that the loss of neomycin resistance occurred at a greater rate at higher temperatures. The proportion of the cells in each culture that had become sensitive to neomycin were 0.25 per cent. at $30^{\circ} \mathrm{C}, 1 \cdot 1$ per cent. at $37^{\circ} \mathrm{C}$, and 4.2 per cent. at $42^{\circ} \mathrm{C}$.

The effect of irradiating a UV-induced lysate of no. $609 \mathrm{~N}_{\mathrm{D}}$ with UV light on its ability to transfer neomycin resistance to no. $609 \mathrm{~S}$ is shown in the figure. Although the element transferring resistance was relatively resistant to UV light, there was no transient rise in the frequency of transduction with increasing UV exposure. Such a curve is characteristic of plasmids (Arber, 1960; Novick, 
1963, 1967). However, this neomycin-resistance determinant is a special case, because no other naturally occurring agent transfers resistance by transduction at such high frequency. Exposure of broth cultures of no. $609 \mathrm{~N}_{\mathrm{D}}$ to either acriflavine or ethidium bromide did not accelerate the loss of neomycin resistance, but some staphylococcal plasmids are not "cured" by these agents (Richmond, 1968; Bouanchaud, Scavizzi and Chabbert, 1969). Since the spontaneous loss of the neomycin resistance was greater at high temperatures and the effect of exposure to UV light on the transfer was similar to its effect

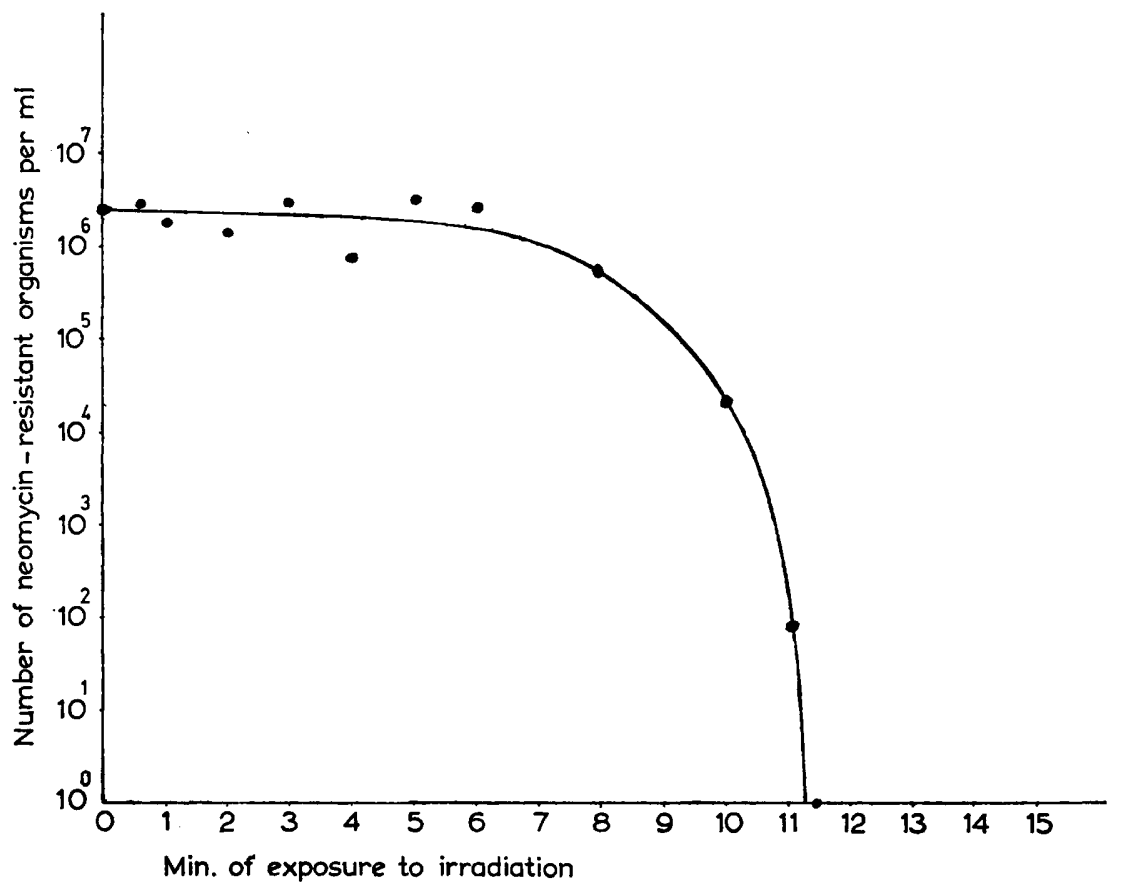

FIGURE.-Effect of UV-irradiation on transfer of neomycin resistance.

A lysate of the donor culture (no. $609 \mathrm{~N}_{\mathrm{D}}$ ) was exposed to UV-irradiation at $25 \mathrm{~cm}$ from a 240 volt Hanovia lamp. 1-ml portions from each exposed lysate were then incubated with the recipient culture (no. 609S) for $30 \mathrm{~min}$. The mixed culture was then plated for neomycin-resistant recipient organisms.

on the rate of transduction of established plasmid-borne markers, it seems probable that the neomycin-resistance determinant was carried on an extrachromosomal element in this strain. Thus the agent transferring resistance may well consist of a complex plasmid partly formed by genes conferring neomycin resistance and in part by phage genome.

\section{Transfer of neomycin resistance between staphylococci on the skin}

Since staphylococci often produce cutaneous sepsis and may be dispersed from the skin in large numbers, the transfer of resistance on the surface of the skin could account for spread of some resistant bacteria. Accordingly 
experiments were performed to determine whether transfer of neomycin resistance could occur experimentally on the surface of the skin.

Colonies that were resistant to both neomycin and streptomycin were recovered only from areas of skin on which both the recipient and the donor strains had been successively inoculated (table IV). The phage-typing pattern and sensitivity to other antibiotics of these colonies were the same as those of the recipient. Since no "spontaneous" neomycin-resistant mutants of the recipient strain were obtained after skin inoculation, it is likely that neomycin resistance in the recipient had been acquired by transfer from the donor whilst

TABLE IV

Transfer of neomycin resistance between two staphylococci seeded on to the same area of skin

\begin{tabular}{|c|c|c|c|}
\hline \multirow{2}{*}{$\begin{array}{l}\text { Initials } \\
\text { of subject } \\
\text { and skin } \\
\text { area no. }\end{array}$} & \multicolumn{3}{|c|}{$\begin{array}{l}\text { No. of colonies of staphylococci resistant to both } \\
\text { streptomycin and neomycin* that were recovered after } \\
6 \text { hr† from skin areas seeded with staphylococcus }\end{array}$} \\
\hline & $\begin{array}{c}\text { no. } 609 \mathrm{~N}_{\mathrm{D}} \\
\text { (neomycin resistant, } \\
\text { streptomycin } \\
\text { sensitive) }\end{array}$ & $\begin{array}{c}\text { no. } 13 \\
\begin{array}{c}\text { (neomycin sensitive, } \\
\text { streptomycin } \\
\text { resistant) }\end{array}\end{array}$ & $\begin{array}{l}\text { no. } 609 \mathrm{~N}_{\mathrm{D}} \\
\text { and no. } 13\end{array}$ \\
\hline J.L. $\left\{\begin{array}{l}1 \\
2 \\
3\end{array}\right.$ & $\begin{array}{l}\mathbf{0} \\
0 \\
0\end{array}$ & $\begin{array}{l}\mathbf{0} \\
\mathbf{0} \\
\mathbf{0}\end{array}$ & $\begin{array}{l}37 \\
65 \\
19\end{array}$ \\
\hline A.T. $\left\{\begin{array}{l}1 \\
2 \\
3\end{array}\right.$ & $\begin{array}{l}\mathbf{0} \\
0 \\
0\end{array}$ & $\begin{array}{l}\mathbf{0} \\
0 \\
\mathbf{0}\end{array}$ & $\begin{array}{l}25 \\
42 \\
11\end{array}$ \\
\hline R.L. $\left\{\begin{array}{l}1 \\
2 \\
3\end{array}\right.$ & $\begin{array}{l}0 \\
0 \\
0\end{array}$ & $\begin{array}{l}\mathbf{0} \\
\mathbf{0} \\
\mathbf{0}\end{array}$ & $\begin{array}{r}1 \\
9 \\
13\end{array}$ \\
\hline
\end{tabular}

* All colonies resembled staphylococcus no. 13 in pigmentation, sensitivity to antibiotics other than neomycin, and phage-typing pattern.

$\dagger$ See Lacey (1968).

on the surface of the skin, and that the mechanism of the transfer on the skin was similar to that in nutrient broth. Although conditions in the above experiments were artificial, the feasibility of transfer of neomycin resistance in clinical situations has been demonstrated.

\section{Discussion}

Several authors have described the spontaneous loss of neomycin and kanamycin resistance from strains of Staph. aureus and have suggested a plasmid locus for the genetic determinants (Chabbert et al., 1964; Evans and Waterworth, 1966; Annear and Grubb, 1969; Ayliffe, 1970), but transfer of neomycin resistance by transduction has not been reported in staphylococci. My attempts to transfer neomycin resistance by transduction from staphylococcus no. $609 \mathrm{~N}_{\mathrm{D}}$ by means of extrinsic phages including no. 53 and 85 in the International Basic Set were also unsuccessful. Perhaps the determinants for neomycin 
resistance in the strains described by the above authors were already closely associated with a phage, as seems probable in the case of staphylococcus no. $609 \mathrm{~N}_{\mathrm{D}}$; and the naturally occurring prophage is not easily displaced by other phages. It is hoped to investigate this possibility in the future.

In Staph. aureus, resistance to several antibiotics other than neomycin is transferable by a variety of generalised transducing phages, but at low frequency. High-frequency transducing agents have rarely been isolated. One of these, the particle conferring erythromycin resistance to sensitive organisms, was artificially created (Novick, 1967; Novick and Morse, 1967), but resembled the naturally occurring agent described here in several properties. However, the former required a specific " helper " prophage for the production of transducing particles. The nature of the agent responsible for the high-frequency transfer of neomycin resistance cannot be precisely defined from the present evidence, but we do know that the transfer is specifically inhibited by antiserum against group-B phages. There are two possibilities: either a variety of phages can act as non-specific helper phages or the neomycin-resistance particle has a phage component that replicates autonomously and presumably in association with the plasmid bearing the resistance determinant. The latter explanation appears the more likely. An analogous situation may occur in Escherichia coli where the temperate phage $\lambda$ can exist and replicate extrachromosomally (Signer, 1969).

The main natural reservoir of staphylococci is the surface of the body, and carriers of Staph. aureus greatly outnumber cases of clinical infection. Most of the staphylococci dispersed into the environment by carriers come from the skin, and some individuals spread large numbers into the air on skin scales (Noble and Davies, 1965). Profuse dispersion also occurs from patients with superficial skin lesions. Novick and Morse demonstrated the transfer of resistance between staphylococci by transduction in systemically infected mice, but staphylococcal lesions in the internal organs are a relatively poor source of dissemination into the environment. That transfer of resistance may also occur on the surface of the skin is of considerable epidemiological importance, because a resistant staphylococcus on the skin is in a position from which spread to fresh hosts is relatively easy.

The acquisition of neomycin resistance by a strain of Staph. aureus affords it a considerable selective advantage on the skin. Neomycin is frequently prescribed topically, and neomycin-resistant staphylococci persist well on neomycin-treated skin (Lacey, 1969b; Marples and Kligman, 1969). Transfer of neomycin-resistance to sensitive staphylococci could occur even in the presence of neomycin, since a proportion of sensitive staphylococci can survive moderate levels of the antibiotic (Lacey, 1969a).

\section{SUMMARY}

A naturally occurring neomycin-resistant strain of Staphylococcus aureus was found to donate its resistance, together with cross-resistance to kanamycin and paromomycin, to a variety of sensitive staphylococci. The transfer occurred spontaneously and at relatively high frequency both in broth cultures and experimentally on the skin surface of volunteers. 
The mechanism of the transfer was transduction, which is believed to be mediated by an element composed of a defective prophage of serological group $\mathrm{B}$ and a determinant for neomycin resistance. The latter is probably located on a plasmid in the resistant cell, since strains harbouring the element tended to lose their resistance spontaneously, particularly at high temperatures. The effect of UV light on the transduction of the element was also characteristic of known plasmids.

The phage-typing patterns of staphylococci able to acquire the neomycinresistance marker in vitro were limited but similar to those of naturally occurring resistant strains. Since neomycin resistance of the type found naturally could not be established in the laboratory, it is probable that the acquisition of neomycin resistance may have occurred in vivo by high-frequency transduction.

I am grateful to Professors M. H. Richmond and W. A. Gillespie for encouragement and critical advice. Dr V. G. Alder supplied some of the strains.

\section{REFERENCES}

ANNEAR, D. I., AND GRUBB, W. B. 1969. Spontaneous loss of resistance to kanamycin and other antibiotics in methicillin-resistant cultures of Staphylococcus aureus. Med. J. Austral., 2, 902.

ARBER, W. 1960. Transduction of chromosomal genes and episomes in Escherichia coli. Virology, 11, 273.

Ayliffe, G. A. J. 1970. Stability of neomycin resistance in Staphylococcus aureus. J. Clin. Path., 23, 19.

BlaIR, J. E., AND Williams, R. E. O. 1961. Phage typing of staphylococci. Bull. Wld Hlth Org., 24, 771.

Bouanchaud, D. H., Scavizzi, M. R., and Chabbert, Y. A. 1969. Elimination by ethidium bromide of antibiotic resistance in enterobacteria and staphylococci. J. Gen. Microbiol., $54,417$.

ChabberT, Y. A. 1967. Bacterial resistance to gentamicin: chromosomal and extrachromosomal. I Int. Symp: Gentamicin, Paris, Lucerne, p. 19.

Chabbert, Y. A., Baudens, J. G., ANd Gerbaud, G. R. 1964. Variations due to acriflavin and transduction of resistance to kanamycin and chloramphenicol in staphylococci. Annls Inst. Pasteur, 107, 678 (in French).

Evans, R. J., AND Waterworth, Pamela M. 1966. Naturally-occurring fusidic acid resistance in staphylococci and its linkage to other resistances. J. Clin. Path., 19, 555.

LACEY, R. W. 1968. Antibacterial action of human skin. In vivo effect of acetone, alcohol and soap on behaviour of Staphylococcus aureus. Br. J. Exp. Path., 49, 209.

LACEY, R. W. 1969a. Dwarf-colony variants of Staphylococcus aureus resistant to aminoglucoside antibiotics and to a fatty acid. J. Med. Microbiol., 2, 187.

LACEY, R. W. 1969b. Loss of the antibacterial action of skin after topical neomycin. $B r . J$. Derm., 81, 435.

Marples, R. R., AND Kligman, A. M. 1969. Pyodermia due to resistant Staphylococcus aureus following topical application of neomycin. J. Invest. Derm., 53, 11.

Miles, A. A., Misra, S. S., AND IRwIN, J. O. 1938. The estimation of the bactericidal power of the blood. J. Hyg., Camb., 38, 732.

Noble, W. C., ANd Davies, R. R. 1965. Studies on the dispersal of staphylococci. J. Clin. Path., 18, 16.

Novick, R. P. 1963. Analysis by transduction of mutations affecting penicillinase formation in Staphylococcus aureus. J. Gen. Microbiol., 33, 121.

Novick, R. P. 1967. Properties of a cryptic high-frequency transducing phage in Staphylococcus aureus. Virology, 33, 155. 
Novick, R. P. 1969. Extrachromosomal inheritance in bacteria. Bact. Rev., 33, 210.

Novick, R. P., AND MorSE, S. I. 1967. In vivo transmission of drug resistance factors between strains of Staphyloccus aureus. J. Exp. Med., 125, 45.

REPORT 1967. Report of the Subcommittee on Phage-typing of Staphylococci of the International Committee on Nomenclature of Bacteria, Moscow, July 1966. Int. J. System. Bact., 17, 113.

RICHMOND, M. H. 1968. The plasmids of Staphylococcus aureus and their relation to other extrachromosomal elements in bacteria. Adv. Microb. Physiol., 2, 43.

RichmoND, M. H. 1969. Extrachromosomal elements and the spread of antibiotic resistance in bacteria. Biochem. J., 113, 225.

Signer, E. R. 1969. Plasmid formation: a new mode of lysogeny by phage $\lambda$. Nature, Lond., 223, 158.

Williams, R. E. O., AND RIPPON, JOAN E. 1952. Bacteriophage typing of Staphylococcus aureus. J. Hyg., Camb., 50, 320.

Willis, A. T., AND TuRner, G. C. 1963. Staphylococci in the hospital environment. $J$. Path. Bact., 85, 395. 